University of Montana

ScholarWorks at University of Montana

Integrative Physiology and Athletic Training

Faculty Publications

Integrative Physiology and Athletic Training

$12-2006$

\title{
Muscle Glycogenolysis and Resynthesis in Response to a Half Ironman Triathlon: A Case Study
}

\author{
Trevor L. Gullum \\ Charles Dumke \\ University of Montana - Missoula, charles.dumke@umontana.edu \\ Brent Ruby \\ University of Montana - Missoula, brent.ruby@umontana.edu
}

Follow this and additional works at: https://scholarworks.umt.edu/hhp_pubs

Part of the Medicine and Health Sciences Commons

Let us know how access to this document benefits you.

\section{Recommended Citation}

Gullum, Trevor L.; Dumke, Charles; and Ruby, Brent, "Muscle Glycogenolysis and Resynthesis in Response to a Half Ironman Triathlon: A Case Study" (2006). Integrative Physiology and Athletic Training Faculty Publications. 4.

https://scholarworks.umt.edu/hhp_pubs/4

This Article is brought to you for free and open access by the Integrative Physiology and Athletic Training at ScholarWorks at University of Montana. It has been accepted for inclusion in Integrative Physiology and Athletic Training Faculty Publications by an authorized administrator of ScholarWorks at University of Montana. For more information, please contact scholarworks@mso.umt.edu. 


\title{
Muscle Glycogenolysis and Resynthesis in Response to a Half Ironman Triathlon: A Case Study
}

\section{Trevor L. Gillum, Charles L. Dumke, and Brent C. Ruby}

\begin{abstract}
Purpose: To describe the degrees of muscle-glycogen depletion and resynthesis in response to a half Ironman triathlon. Methods: One male subject (38 years of age) completed the Grand Columbian half Ironman triathlon (1.9-km swim, $90-\mathrm{km}$ bike, 21.1-km run, Coulee City, Wash). Three muscle biopsies were obtained from his right vastus lateralis (prerace, immediately postrace, and 4 hours postrace). Prerace and postrace body weight were recorded, in addition to macronutrient consumption before, during, and after the race. Energy expenditure and whole-body substrate oxidation were estimated from linear regression established from laboratory trials (watts and run pace relative to $\mathrm{VO}_{2}$ and $\mathrm{VCO}_{2}$ ). Results: Body weight decreased $3.8 \mathrm{~kg}$ from prerace to postrace. Estimated CHO energy expenditure was 10,003 $\mathrm{kJ}$ for the bike segment and $5759 \mathrm{~kJ}$ for the run segment of the race. The athlete consumed $308 \mathrm{~g}$ of exogenous $\mathrm{CHO}$ (liquid and gel; $1.21 \mathrm{~g} \mathrm{CHO} / \mathrm{min}$ ) during the race. Muscle glycogen decreased from 227.1 prerace to $38.6 \mathrm{mmol} \cdot \mathrm{kg}$ wet weight ${ }^{-1} \cdot h^{-1}$ postrace. During the 4 hours postrace, the athlete consumed a mixed diet (471 $\mathrm{g}$ CHO, $15 \mathrm{~g}$ fat, $64 \mathrm{~g}$ protein), which included liquid $\mathrm{CHO}$ sources and a meal. The calculated rate of muscle-glycogen resynthesis was $4.1 \mathrm{mmol} \cdot \mathrm{kg}$ wet weight ${ }^{-1} \cdot \mathrm{h}^{-1}$. Conclusion: Completing a half Ironman triathlon depends on a high rate of muscle glycogenolysis, which demonstrates the importance of exogenous carbohydrate intake during the race. In addition, rates of muscle-glycogen resynthesis might be dampened by the eccentric damage resulting from the run portion of the race.
\end{abstract}

Key Words: endurance training, physical performance, nutrition, metabolism, exercise physiology, exercise performance, hydration, carbohydrate feedings, glycogen resynthesis

The triathlon is a distinct sporting event combining 3 disciplines (swimming, cycling, and running) that impose unique metabolic and nutritional concerns for working muscles, depending on the duration of the event. Kimber et al ${ }^{1}$ have

Gillum and Ruby are with the Human Performance Laboratory, University of Montana, Missoula, MT 59812. Dumke is with the Dept of Health, Leisure, and Exercise Science, Appalachian State University, Boone, NC 28608. 
reported a mean energy intake of $16,500 \mathrm{~kJ}$ and an estimated energy expenditure of $42,050 \mathrm{~kJ}$ for male triathletes during a full Ironman triathlon. The half Ironman triathlon consists of a $1.9-\mathrm{km}$ swim followed by a $90-\mathrm{km}$ cycle and $21.1-\mathrm{km}$ run.

Fatigue during prolonged, intense exercise is associated with glycogen depletion in working skeletal muscles. ${ }^{2}$ Moreover, muscle glycogen is the most important substrate for contracting muscle during moderate to heavy exercise. ${ }^{2}$ Although endogenous glycogen stores are limited, prerace diet can increase these stores, proper training can attenuate their use, and feeding during the race might decrease the rate of muscle-glycogen depletion. The purpose of this study was to describe the degrees of muscle-glycogen depletion and resynthesis in response to a half Ironman triathlon.

\section{Methodology}

One experienced, recreationally competitive, 38 -year-old male subject completed a half Ironman triathlon (1.9-km swim, 90-km bike, and 21.1-km run, Grand Columbian, Coulee City, Wash). The subject's recent training history included a mean volume of $20 \mathrm{~h} / \mathrm{wk}$ (including a mean $6000 \mathrm{~m} / \mathrm{wk}$ swimming, 298 to 402 $\mathrm{km} / \mathrm{wk}$ cycling, 64 to $80 \mathrm{~km} / \mathrm{wk}$ running for the last 3 months leading up to the race). Before the race, the subject, in a carbohydrate-fed state similar to prerace conditions but not ingesting supplements during the laboratory tests, underwent descriptive laboratory testing to determine peak oxygen uptake $\left(\mathrm{VO}_{2}\right.$ peak) and ventilatory threshold (VT) on an electronically braked cycle ergometer (initiated at $50 \mathrm{~W}$ and progressed at a rate of $30 \mathrm{~W} / \mathrm{min}$ in ramp protocol; Velotron, Seattle, Wash) and motorized treadmill (initiated at a speed of $3.6 \mathrm{~m} / \mathrm{s}, 1 \%$ grade, and progressed at a rate of $0.22 \mathrm{~m} / \mathrm{s}$ each minute until $4.7 \mathrm{~m} / \mathrm{s}$, after which the grade was increased $1 \%$ every 30 seconds until volitional exhaustion (Quinton treadmill, Seattle, Wash). In addition to the maximal exercise testing, on a separate day the subject completed 4 steady-state exercise stages (7- to 10-minute stages) on the cycle and treadmill. Using these steady-state data, linear-regression equations were established for cycle watts and treadmill running pace relative to submaximal, steady-state measures of $\mathrm{VO}_{2}, \mathrm{VCO}_{2}$, and heart rate. Despite not accounting for alterations in substrate oxidation over time (because of the duration of exercise and changes in core temperature), these regression equations were used to estimate rates of whole-body substrate oxidation and total energy expenditure during the cycle and run portions of the race. Descriptive characteristics of the subject are shown in Table 1.

Table 1 Subject Descriptive Data

\begin{tabular}{lcccccc}
\hline Age & $\begin{array}{c}\text { Height } \\
(\mathrm{cm})\end{array}$ & $\begin{array}{c}\text { Weight } \\
(\mathbf{k g})\end{array}$ & $\begin{array}{c}\text { Peak Vo } \\
\text { bike } \\
\text { L/min) }\end{array}$ & $\begin{array}{c}\text { Peak Vo }_{2}, \\
\text { run } \\
(\mathrm{L} / \mathrm{min})\end{array}$ & $\begin{array}{c}\text { Ventilatory } \\
\text { threshold, } \\
\text { bike } \\
(\mathrm{L} / \mathrm{min})\end{array}$ & $\begin{array}{c}\text { Ventilatory } \\
\text { threshold, } \\
\text { run } \\
(\mathrm{L} / \mathrm{min})\end{array}$ \\
\hline 38 & 185.4 & 78.8 & 4.83 & 4.92 & 3.01 & 3.42 \\
\hline
\end{tabular}




\section{Prerace}

During the 48 hours before the race, the subject was prescribed a nutritional intake that provided no less than $10 \mathrm{~g} / \mathrm{kg}$ body weight each day. On race day, approximately 90 minutes before the start of the race, after the athlete had eaten breakfast, a prerace muscle biopsy was obtained from the right vastus lateralis. ${ }^{3}$ Muscle samples were immediately frozen in liquid nitrogen and stored at $-85^{\circ} \mathrm{C}$ for later analyses. After the muscle biopsy, a measure of body weight was obtained. The macronutrient content of the subject's breakfast was quantified from a detailed food-intake inventory and analyzed using Food Processor Pro software.

\section{Race}

During the race, carbohydrate-consumption patterns were recorded from a preestablished intake plan amounting to approximately $1.2 \mathrm{~g} / \mathrm{min}$. Deviations from the intake plan were recorded from the subject's dietary recall during the race. Energy intake prerace, postrace, and 4 hours postrace is shown in Table 2. In addition, cycle power output (SRM power systems, Colorado Springs, Col) and heart rate (Polar S810i, Finland) were continually measured. Running pace was monitored by the subject using a digital running watch and mile-lap-split recordings. The run leg was performed on a flat, groomed bike path with good footing.

\section{Postrace}

Immediately after the race, a postrace measure of body weight was obtained with the athlete wearing the same clothing as prerace. A postrace biopsy was then obtained (from a second incision $2 \mathrm{~cm}$ proximal to the preexercise incision), after which the subject consumed a standardized diet (total $=471 \mathrm{~g} \mathrm{CHO}, 15 \mathrm{~g}$ fat, $64 \mathrm{~g}$ protein) that included hourly liquid $\mathrm{CHO}$ sources (Gatorade $\otimes$ energy drink, $0.22 \mathrm{~g} \mathrm{CHO} / \mathrm{mL}$ ) and a meal provided by the race organizers. Total carbohydrate intake during this 4-hour refeeding period was $6.3 \mathrm{~g} / \mathrm{kg}\left(1.6 \mathrm{~g} \cdot \mathrm{kg}^{-1}\right.$ $\cdot \mathrm{h}^{-1}$ ). Four hours postrace, a third biopsy was obtained (from a third incision $2 \mathrm{~cm}$ proximal to the postexercise incision). Muscle glycogen was analyzed in triplicate using an enzymatic spectrophotometric method as has been previously described. ${ }^{4}$

\section{Table 2 Self-Selected Energy Intake Before, During, and After the Race}

\begin{tabular}{lccc}
\hline & Prerace & $\begin{array}{c}\text { During } \\
\text { race }\end{array}$ & $\begin{array}{c}\mathbf{4 h} \\
\text { postrace }\end{array}$ \\
\hline Energy intake $(\mathrm{kJ})$ & 2386 & 4861 & 9546 \\
CHO (g) & $110 \mathrm{~g}$ & $307.91 \mathrm{~g}$ & $471 \mathrm{~g}$ \\
\hline
\end{tabular}




\section{Results}

Overall finish time for the race was 4:48:53 (33:33 swim, 2:43:11 bike, 1:28:40 run). The subject averaged $230 \mathrm{~W}\left(110 \% \mathrm{VT}, 68 \% \mathrm{VO}_{2}\right.$ peak $)$ for the cycle portion of the race and $14.24 \mathrm{~km} / \mathrm{h}\left(101 \% \mathrm{VT}, 70 \% \mathrm{VO}_{2}\right.$ peak) for the running portion. Body weight decreased $3.8 \mathrm{~kg}$ from prerace to postrace ( $4.9 \%$ weight loss). The ambient air temperature fluctuated throughout the race and was $13.9^{\circ} \mathrm{C}$ at the $09: 30 \mathrm{start}$, $22.2^{\circ} \mathrm{C}$ at $12: 00$, and $23.9^{\circ} \mathrm{C}$ at the finish. Estimated $\mathrm{CHO}$ energy expenditure (EE) was $10,003 \mathrm{~kJ}$ ( $641 \mathrm{~g} \mathrm{CHO}, 88 \%$ of total cycle EE) for the bike segment and 5,759 $\mathrm{kJ}$ ( $369 \mathrm{~g} \mathrm{CHO}, 86 \%$ of total run EE) for the run segment of the race. During the race, the athlete consumed $308 \mathrm{~g} \mathrm{CHO}$ (sports drink and gel products), averaging $1.2 \mathrm{~g} / \mathrm{min}$ during the run and bike portions of the race. Total run and bike CHO $\mathrm{EE}$ was estimated at $15,762 \mathrm{~kJ}(1010 \mathrm{~g})$, and energy intake during the race was estimated at $4,895 \mathrm{~kJ}(418 \mathrm{~g})$, or $31 \%$ of the total CHO EE.

Muscle glycogen demonstrated an $83 \%$ decrease from 227.1 prerace to 38.6 $\mathrm{mmol} / \mathrm{kg}$ wet weight postrace. During the 4 hours postrace, muscle glycogen demonstrated an increase to $54.90 \mathrm{mmol} / \mathrm{kg}$ wet weight, $24 \%$ of prerace values, with a calculated rate of resynthesis of $4.1 \mathrm{mmol} \cdot \mathrm{kg}$ wet weight ${ }^{-1} \cdot \mathrm{h}^{-1}$.

\section{Discussion}

The main findings from this case study indicate that completing a half Ironman triathlon is associated with a high rate of whole-body $\mathrm{CHO}$ oxidation and muscle glycogenolysis. Furthermore, this demonstrates the importance of prerace nutritional strategies to maximize glycogen storage, coupled with an aggressive exogenous $\mathrm{CHO}$ intake schedule during the race to maintain $\mathrm{CHO}$ oxidation and exercise intensity.

Past research has suggested a feeding schedule amounting to 60 to $70 \mathrm{~g} / \mathrm{h}$ of $\mathrm{CHO}$ during prolonged exercise because maximal rates of exogenous $\mathrm{CHO}$ oxidation average 1.0 to $1.1 \mathrm{~g} / \mathrm{min}^{5}$ If the $\mathrm{CHO}$ solution includes a mixture of 3 parts glucose, 1 part fructose, however, a higher rate of exogenous $\mathrm{CHO}$ oxidation is possible ( $20 \%$ to $50 \%$ increase in oxidation to approximately $1.50 \mathrm{~g} / \mathrm{min}$ ) than with the ingestion of an isocaloric glucose solution. ${ }^{6}$ It appears that glucose and fructose are absorbed by different intestinal transport mechanisms, which might lead to faster transport and subsequent oxidation of exogenous $\mathrm{CHO}$ sources by the active skeletal muscle. ${ }^{6}$ This type of strategy to maximize the rates of exogenous $\mathrm{CHO}$ oxidation might be crucial during this type of exercise. Although the importance of exogenous $\mathrm{CHO}$ is clear, we cannot conclude from these descriptive data whether the intake of exogenous $\mathrm{CHO}$ decreased the rate of muscle glycogenolysis. Although the consumption of exogenous CHO $(1.21 \mathrm{~g} / \mathrm{min}$ glucose and fructose mixture, 3:1) might have maximized the rate of exogenous $\mathrm{CHO}$ oxidation during the race, there was a noticeable decrement in running performance. Average split times were $6: 17,6: 44$, and $7: 10 \mathrm{~min} / \mathrm{mile}$ for miles 1 to 3,6 to 8 , and 10 to 13 , respectively. This fatigue might be associated with but not limited to the combination of dehydration, central-nervous-system fatigue, diminished muscle glycogen, or elevated core body temperature. Fatigue was not likely related, however, to 
inadequate exogenous $\mathrm{CHO}$ intake as it approached the reported maximal rates previously recommended. ${ }^{6}$

Total CHO availability (g) was supplemented by a combination of a prerace meal $(110 \mathrm{~g} \mathrm{CHO})$ and feedings during the race $(308 \mathrm{~g} \mathrm{CHO})$, which represented $41 \%$ of the total $\mathrm{CHO}$ oxidized during the cycle and run portions of the race, not accounting for additional $\mathrm{CHO}$ oxidation during the swim. This is in agreement with previous findings reporting that high rates of $\mathrm{CHO}$ oxidation can be maintained during the latter stages of prolonged continuous exercise when muscle glycogen stores are very low. ${ }^{7} \mathrm{CHO}$ supplementation during prolonged exercise can partially compensate for the reduction of endogenous $\mathrm{CHO}$ stores and delay fatigue by maintaining plasma-glucose availability. It appears, however, that consuming exogenous $\mathrm{CHO}$ at a rate of approximately $1.2 \mathrm{~g} / \mathrm{min}$ might not fully compensate for the negative effects of glycogen depletion, which might have, in part, caused impaired running performance late in the race. Nonetheless, it is important to consider the other possible contributors to this late-race fatigue; the possibility of an endogenous $\mathrm{CHO}$-sparing effect caused by consuming exogenous $\mathrm{CHO}$ appears unlikely under competitive racing conditions. ${ }^{7}$

In addition, researchers have shown that the effects of eccentric muscle damage might dampen the rates of muscle-glycogen resynthesis. ${ }^{8}$ The calculated rate of muscle-glycogen resynthesis was $4.1 \mathrm{mmol} \cdot \mathrm{kg}$ wet weight $t^{-1} \cdot \mathrm{h}^{-1}$. The prolonged eccentric contractions during the run portion of the race could account for the lower rate of muscle-glycogen resynthesis reported than in some of our earlier work with a high-intensity cycling protocol, which demonstrated a much higher rate of muscle-glycogen resynthesis $\left(10.6 \mathrm{mmol} \cdot \mathrm{kg}\right.$ wet weight $\left.{ }^{-1} \cdot \mathrm{h}^{-1}\right){ }^{4}$ Similar results have suggested that eccentric contractions dampen the rate of muscle-glycogen resynthesis when the traumatized muscle is penetrated with inflammatory cells, which oxidize glucose. Eccentric damage presents a competition between the inflammatory cells and the glycogen-depleted muscle fibers for blood glucose, reducing the amount of available glucose for muscle-glycogen storage. ${ }^{8}$ Researchers have also shown that $\mathrm{CHO}$ intake during prolonged exercise might diminish the rates of postexercise muscle-glycogen resynthesis, compared with prolonged exercise in a fasted state. The mean rate of muscle-glycogen resynthesis during the initial 4-hour recovery period after the fasting exercise bout was found to be $\approx 3$-fold higher than after exercise combined with carbohydrate ingestion, perhaps as a result of enhanced insulin action. ${ }^{9}$

\section{Practical Applications and Conclusions}

Completing a half Ironman triathlon requires a high rate of whole-body CHO oxidation and muscle glycogenolysis. This case study, data demonstrate the importance of prerace and race nutritional strategies to maximize prerace glycogen concentrations and the availability of exogenous $\mathrm{CHO}$. The dampened rate of postrace muscle-glycogen resynthesis might result in part from the eccentric muscle damage or exogenous intake during the triathlon. 


\section{Acknowledgments}

This research was funded in part by a grant from the Gatorade Sports Science Institute. Special thanks to Scott USA for the CR1 Plasma LTD time-trial bicycle used for this study.

\section{References}

1. Kimber N, Ross $\mathbf{J}$, Sue $\mathbf{M}$, et al. Energy balance during an Ironman triathlon in male and female triathletes. Int J Sport Nutr Exerc Metab. 2002;12:47-62.

2. Hermansen L, Hultman E, Saltin B. Muscle glycogen during prolonged severe exercise. Acta Physiol Scand. 1967;71(2):129-139.

3. Bergstrom J. Percutaneous needle biopsy of skeletal muscle in physiological and clinical research. Scand J Clin Lab Invest. 1975;35(7):609-616.

4. Ruby B, Gaskill S, Slivka D, Harger S. The addition of fenugreek extract (Trigonella foenum-graecum) to glucose feeding increases muscle glycogen resynthesis after exercise. Amino Acids. 2005;28(1):71-76.

5. Jeukendrup A, Jentjens $R$. Oxidation of carbohydrate feedings during prolonged exercise: current thoughts, guidelines, and directions for future research. Sports Med. 2000;29(6):407-424.

6. Jentjens R, Moseley L, Waring R, et al. Oxidation of combined ingestion of glucose and fructose during exercise. J Appl Physiol. 2004;96(4):1277-1284.

7. Coyle E, Coggan A, Hemmert M, Ivy J. Muscle glycogen utilization during prolonged strenuous exercise when fed carbohydrate. $J$ Appl Physiol. 1986;61(1):165-172.

8. Costill D, Pascoe D, Fink J, et al. Impaired muscle glycogen resynthesis after eccentric exercise. J Appl Physiol. 1990;69(1):46-50.

9. De Bock K, Richter E, Russell A, et al. Exercise in the fasted state facilitates fiber type-specific intramyocellular lipid breakdown and stimulates glycogen resynthesis 